\title{
Synthesis, characterization and thermal decomposition of poly(decamethylene 2,6-naphthalamide)
}

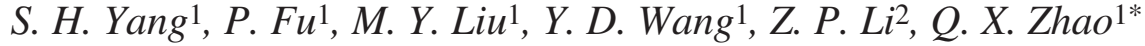 \\ ${ }^{1}$ School of Materials Science and Engineering, Zhengzhou University, 75 Daxue Road, Zhengzhou 450052, \\ People's Republic of China \\ ${ }^{2}$ Radiation Processing Center, Henan Academy of Sciences, 7 Songshan Road, Zhengzhou 450015, \\ People's Republic of China
}

Received 8 February 2010; accepted in revised form 29 March 2010

\begin{abstract}
A novel engineering plastic, poly(decamethylene 2,6-naphthalamide) (PA10N) was prepared via a reaction of 2,6-naphthalene dicarboxylic acid and 1,10-decanediamine. The structure of synthesized PA10N was characterized by elemental analysis, Fourier transform infrared (FT-IR) spectroscopy and proton nuclear magnetic resonance $\left({ }^{1} \mathrm{H}-\mathrm{NMR}\right)$. The thermal behavior was determined by differential scanning calorimetry (DSC), thermo-gravimetric analysis (TGA) and dynamic mechanical analysis (DMA). Melting temperature $\left(T_{m}\right)$, glass transition temperature $\left(T_{g}\right)$ and decomposition temperature $\left(T_{d}\right)$ of PA10N are 320,144 and $495^{\circ} \mathrm{C}$, respectively. The solubility, water-absorbing capacity, and mechanical properties of PA10N have also been investigated. Pyrolysis products and thermal decomposition mechanism of PA10N were analyzed by flash pyrolysis-gas chromatography/mass spectrometry (Py-GC/MS). The results show that the heat resistance and mechanical properties of PA10N are near to those of poly(nonamethylene terephthalamide) (PA9T), and $\mathrm{PA} 10 \mathrm{~N}$ is a promising heat-resistant and processable engineering plastic.
\end{abstract}

Keywords: mechanical properties, thermal properties, polyamides, synthesis, decomposition

\section{Introduction}

Aromatic polyamides and semiaromatic polyamides have been widely used in many industrial and commercial applications, especially in surface-mount technology (SMT) and automobile industries, by virtue of their excellent characteristics such as good thermal stability, chemical resistance, low creep and high modulus [1-3]. The commonly mentioned aromatic and semiaromatic polyamides can not be processed by melting method due to their high melting temperature and relatively lower decomposition temperatures [4-6]. Therefore, several approaches have been made through synthetic modification by the incorporation of flexible linkages [7, 8], bulky pendant groups [9] and noncoplanar biphenylene moieties [10] into the polymer backbones. Poly(nonamethylene terephthalamide) (PA9T) inherits the merits of the heat resistance of aromatic polyamides and the processing ability of aliphatic polyamides [11]. However, the high cost of PA9T limited its applications.

In order to increase the processing ability and decrease the cost of semiaromatic polyamides, long flexible aliphatic chains are usually introduced into their backbones [12-14]. It has been reported that diacids with long molecular chains can be prepared from petroleum fermentation process using light wax as raw material [15], and the long chain diamines can be prepared from the corresponding long chain diacids by cyanation and amination process [16]. The cost of obtained long chain diacids and diamines was reduced accordingly. It 
was noticeable that naphthalene-ring can be also introduced into the molecular main chain of semiaromatic polyamides and high thermal stability was retained expectably. However, the semiaromatic polyamides containing naphthalene-ring were presented relatively low molecular weight and unsatisfactory performance which would not meet the requirements for commercialization $[17,18]$. Therefore, it is of great significance to synthesize novel, low-cost, high-performance and processability semiaromatic polyamides containing naphthalenering.

Semiaromatic polyamides are widely used in many demanding applications where the properties of thermal stability and flame resistant are priorities [19]. Taking into account this high practical interest, it is important to study the thermal decomposition behavior of semiaromatic polyamides [20,21]. Pyrolysis-gas chromatography/mass spectrometry (Py-GC/MS) is well established as a method for the analysis of the thermal decomposition of polymers [22-24]. The investigation of Py-GC/MS can provide unique information on the primary processes of the thermal decomposition of polymers and also important structural information, such as structural identification of homopolymers, differentiation of isomeric structures, copolymer composition, etc.

In this work, the PA10N was successfully synthesized by the polycondensation reaction of 2,6-naphthalene dicarboxylic acid and 1,10-decanediamine in water. PA10N was investigated by Fourier transform infrared (FT-IR) spectroscopy, proton nuclear magnetic resonance $\left({ }^{1} \mathrm{H}-\mathrm{NMR}\right)$ and elemental analysis. The thermal property was studied by differential scanning calorimetry (DSC), thermogravimetric analysis (TGA) and dynamic mechanical analysis (DMA). The thermal decomposition process was analyzed by Py-GC/MS. The solubility, intrinsic viscosity, inherent viscosity, waterabsorbing capacity and mechanical properties of PA10N were also studied.

\section{Materials and methods}

\subsection{Materials}

2,6-naphthalene diacrboxylic acid was purchased from Mitsubishi Gas Chemical Company, Inc (MGC, Japan). 1,10-decanediamine was provided commercially by Zibo Guangtong Chemical Co.
Ltd (China), and purified by vacuum distillation prior to use.

\subsection{Synthesis of PA10N}

PA10N was prepared from the reaction of 2,6naphthalene dicarboxylic acid and 1,10-decanediamine through a three-step procedure: salt formation, prepolymerization and solid-state polymerization (Figure 1).

1,10-decanediamine ( $258 \mathrm{~g}, 1.5 \mathrm{~mol})$ was dissolved in distilled water $(1000 \mathrm{ml})$ at $80^{\circ} \mathrm{C}$. Then the solution was added slowly into $500 \mathrm{ml}$ of distilled water mixture of 2,6-naphthalene diacrboxylic acid ( $324 \mathrm{~g}$, $1.5 \mathrm{~mol}$ ) with vigorous stirring and then stirred for $2 \mathrm{~h}$ at $80^{\circ} \mathrm{C}$. Finally a slight excess of 1,10 -decanediamine ( $2 \mathrm{~g}, 0.01 \mathrm{~mol})$ was added into the solution with continuous stirring for $1 \mathrm{~h}$ at $80^{\circ} \mathrm{C}$. The $\mathrm{pH}$ value of the solution was adjusted to 7.2. The white 1,10-decanediamine-2,6-naphthalene diacrboxylic acid salt (PA10N salt) precipitated from the solution.

After filtering over a Buchner funnel and drying in a vacuum desiccator for $12 \mathrm{~h}$, the white salt of PA10N $(553 \mathrm{~g})$ and distilled water $(500 \mathrm{ml})$ were added into an autoclave. The autoclave was filled with carbon dioxide and then heated to $240^{\circ} \mathrm{C}$ while increasing the pressure to $2.6 \mathrm{MPa}$. After $2 \mathrm{~h}$, the pressure of the autoclave was gradually decreased to normal pressure in $2 \mathrm{~h}$ by deflating and the reaction temperature of the autoclave was increased to $255^{\circ} \mathrm{C}$. After reaction for another $1.5 \mathrm{~h}$, the ivory-white prepolymer of PA10N was obtained (503 g).

The prepolymer of PA10N was ground into particles with diameter of $0.1 \sim 2 \mathrm{~mm}$ and dried at $90^{\circ} \mathrm{C}$ in a vacuum oven for $4 \mathrm{~h}$. Then the prepolymer of PA10N was added into a solid-state polymerization kettle, the reaction was carried out at $250^{\circ} \mathrm{C}$ for $15 \mathrm{~h}$ with a vacuum of $10 \mathrm{~Pa}$. Finally, the kettle was cooled to room temperature and straw yellow polymer of PA10N was obtained (478 g).

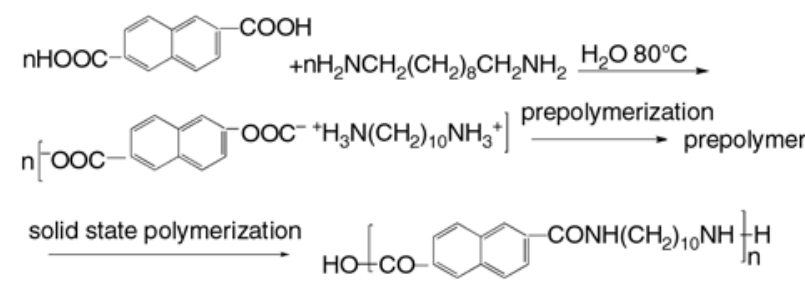

Figure 1. The synthetic route of PA10N 


\subsection{Characterization of PA10N}

FT-IR, ${ }^{1} \mathrm{H}-\mathrm{NMR}$ and elemental analysis were used to confirm the structure of PA10N. The thermal behavior was determined by DSC, TGA and DMA. Thermal decomposition mechanisms of PA10N were analyzed by Py-GC/MS. The solubility, intrinsic viscosity, inherent viscosity, water-absorbing capacity and mechanical property of PA10N were also studied.

The intrinsic viscosity and inherent viscosity of PA10N dissolved in concentrated sulfuric acid was determined in an Ubbelohde viscometer at $25 \pm 0.1^{\circ} \mathrm{C}$. The water-absorbing of PA10N was measured according to GB/T 1034 (Chinese standard).

The FT-IR measurement was carried out on a NICOLET 460 spectrometer. ${ }^{1} \mathrm{H}-\mathrm{NMR}$ spectra was recorded with a Bruker DPX-400 (400 MHz), using deuterated trifluoroacetic acid as solvents and tetramethylsilane (TMS) as an internal reference. Elemental analysis was performed on a PerkinElmer $2400 \mathrm{CHNS} / \mathrm{O}$ elemental analyzer at $975^{\circ} \mathrm{C}$ under nitrogen.

Thermal analysis (DSC and TGA) was recorded on a NETSCH 204 calorimeter with a heating rate of $10^{\circ} \mathrm{C} \cdot \mathrm{min}^{-1}$ in a nitrogen stream. DMA was carried out on a NETZSCH DMA-242 apparatus operating in the bending mode at $1 \mathrm{~Hz}$ and a heating rate $3^{\circ} \mathrm{C} \cdot \mathrm{min}^{-1}$ from -170 to $170^{\circ} \mathrm{C}$.

All samples for mechanical tests were prepared by injection molding. The Izod impact strength was measured according to GB/T 1843 (Chinese standard). Tensile strength and elongation at break were measured according to GB/T 1040 (Chinese standard). Bending strength was measured according to GB/T 9341 (Chinese standard). All tests were carried out at room temperature $\left(23^{\circ} \mathrm{C}\right)$. The resulting value of each sample was the average of five parallel experiments.

The samples of PA10N were pyrolyzed with a setpoint of $700^{\circ} \mathrm{C}$ per $5 \mathrm{~s}$ using a Chemical Data Systems Pyroprobe 2000. Pyrolyses were carried out in helium using a coil probe. The sample weights used ranged from 0.1 to $1 \mathrm{mg}$, and no changes in pyrolysis product distribution were observed. Analysis was performed using an Agilent GC/MS(6890A/ 5973) system with a DB-FFAP (nitroterephthalic acid modified polyethylene glycol) capillary columns from J\&W Company $(60 \mathrm{~m} \times 250 \mu \mathrm{m} \times$
$0.25 \mu \mathrm{m})$. The oven temperature program was as follows: $40^{\circ} \mathrm{C}$, initial time $5 \mathrm{~min}$, heating rate $3^{\circ} \mathrm{C} \cdot \mathrm{min}^{-1}$, then temperature $200^{\circ} \mathrm{C}$ holding $10 \mathrm{~min}$, final temperature $230^{\circ} \mathrm{C}$ for $20 \mathrm{~min}$. Helium was used as the carrier gas. Mass spectra was acquired by a Nist 98 Mass Spectra Library data system operating under HP Chemistry Station G1034. The mass spectrometer was scanned repetitively from $\mathrm{m} / \mathrm{z} 500$ to $\mathrm{m} / \mathrm{z}, 20$ at a scan rate of $0.7 \mathrm{~s} /$ decade; the ionizing conditions were $70 \mathrm{eV}$.

\section{Results and discussion}

\subsection{Synthesis of PA10N}

PA10N was prepared from the reaction of 2,6naphthalene dicarboxylic acid and 1,10-decanediamine through a three-step procedure: salt formation, prepolymerization and solid-state polymerization. In order to assure an accurate equivalent ratio of 1,10-decanediamine to 2,6-naphthalene dicarboxylic acid, PA10N salt was prepared firstly. Then an slight excess 1,10-decanediamine was added into the salt solution to compensate reaction system for the loss during the prepolymerization reaction. It is noticeable that the solvent for the salt formation reaction is water, which is cheaper and environmental friendly compared with ethanol, usually used in preparing other common polyamides [25]. In order to obtain high vapor pressure, the distilled water was added to reduce volatilization of diamine during the prepolymerization. The prepolymer was ground into small particles, which are convenient for removing water. In order to avoid side reaction and to improve the molecular weight of the polyamide, the high vacuum was maintained during the solid-state polymerization reaction. The molecular weight of the PA10N was characterized by intrinsic viscosity and inherent viscosity. The intrinsic viscosity and inherent viscosity of PA10N are $1.85 \mathrm{dl} \cdot \mathrm{g}^{-1}$ and about $1.78 \mathrm{dl} \cdot \mathrm{g}^{-1}$, respectively. FT-IR spectrum of the PA10N is shown in Figure 2. All the characteristic peaks of amide groups and methylene segments of polyamide are listed as follows: $1632 \mathrm{~cm}^{-1}$ (amide I, $\mathrm{C}=\mathrm{O}$ stretching vibration), $1534 \mathrm{~cm}^{-1}$ (amide II, C-N stretching and $\mathrm{CO}-\mathrm{N}-\mathrm{H}$ bending vibration), $2922 \mathrm{~cm}^{-1}(\mathrm{~N}-\mathrm{H}$ inplane bending vibration and $\mathrm{CH}_{2}$ vibration), $3296 \mathrm{~cm}^{-1}$ (hydrogen-bonded and $\mathrm{N}-\mathrm{H}$ stretching vibration), $3076 \mathrm{~cm}^{-1}$ ( $\mathrm{N}-\mathrm{H}$ in-plane bending), 


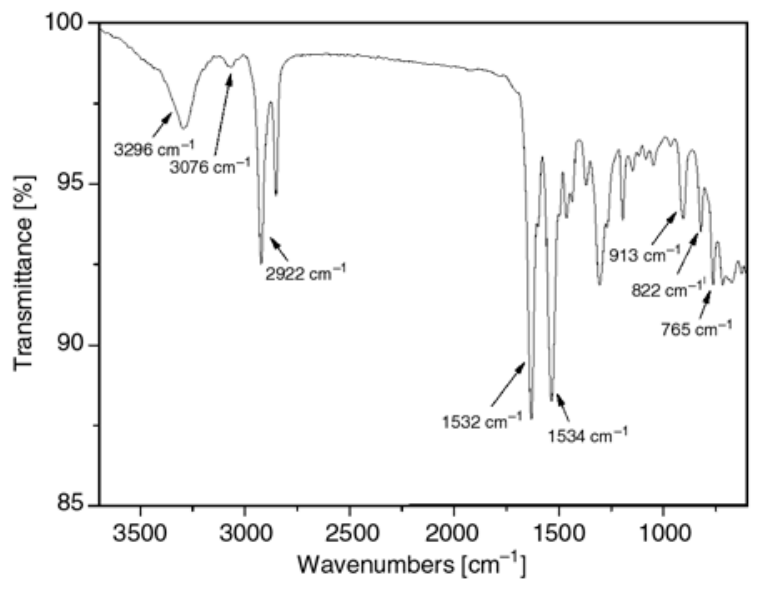

Figure 2. FT-IR spectra of PA10N

$912 \mathrm{~cm}^{-1}$ (amide IV, C-CO stretching vibration), $822 \mathrm{~cm}^{-1}\left(\mathrm{CH}_{2}\right.$ wagging $), 765 \mathrm{~cm}^{-1}(\mathrm{C}-\mathrm{H}$ of naphthalene ring vibration).

Figure 3 presents the ${ }^{1} \mathrm{H}-\mathrm{NMR}$ spectrum of PA10N in deuterated trifluoroacetic acid. The chemical shifts at $8.50 \mathrm{ppm}(2 \mathrm{H}), 7.96 \mathrm{ppm}(2 \mathrm{H})$ and $8.19 \mathrm{ppm}(2 \mathrm{H})$ are attributed to the naphthalene ring protons $(a, b$ and $c$ ). The chemical shift at $3.83 \mathrm{ppm}(4 \mathrm{H})$ originates from the protons at the position $d$ while that at $1.93 \mathrm{ppm}(4 \mathrm{H})$ comes from the protons at the position $e$. The peak at $1.49 \mathrm{ppm}$ $(12 \mathrm{H})$ belongs to the other protons of the aliphatic chains $(f)$. The peak at $11.6 \mathrm{ppm}$ was assigned to trifluoroacetic acid.

The elemental analysis data of PA10N are listed in Table 1. The calculated components are presented for comparison. The resulting value of elemental analysis was the average of five parallel experi-

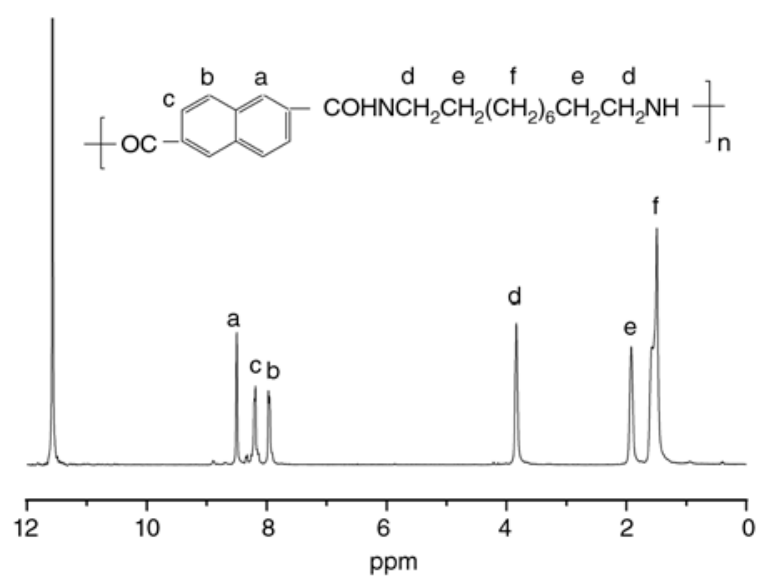

Figure 3. ${ }^{1} \mathrm{H}-\mathrm{NMR}$ spectra of PA10N ments. The hydrogen content of PA10N is higher than the theoretical value owing to the absorption of water. The other measurement results are in agreement with the theoretical values.

The water-absorbing of PA10N was measured according to GB/T 1034 (Chinese standard), and the result is 0.14 . The low water absorption, close to PA9T (0.17) [26], is conducive to maintain dimensional and mechanical stability of products. The solubilities (sample $100 \mathrm{mg}$, solvent $10 \mathrm{ml}$ ) of PA10N were tested in different organic solvents. PA10N can easily dissolve in acidic solvents such as concentrated sulfuric acid and trifluoroacetic acid (TFA) at room temperature, while it is insoluble in dimethylsulphoxide (DMSO), N, $\mathrm{N}^{\prime}$-dimethylformamide (DMF), 1-methyl-2-pyrrolidenone (NMP), dimethylacetamide (DMAc), $m$-cresol, tetrahydrofuran (THF), pyridine, tetrachloroethane, chlorobenzene, methanol, toluene, chloroform, phenol and formic acid. The results show that PA10N exhibits good chemical solvent resistance.

\subsection{Thermal properties of PA10N}

Figure 4 depicts the DSC curves of PA10N. Curve A is the second heating DSC curve, while B is a cooling DSC curve. The heating rate is $10^{\circ} \mathrm{C} \cdot \mathrm{min}^{-1}$, and the test temperature is 50 to $330^{\circ} \mathrm{C}$. PA $10 \mathrm{~N}$ exhibits double-melting endotherms, which is a common phenomenon observed in semicrystalline polymers [27-29]. The melting temperature $\left(T_{m}\right)$ of PA10N is $320^{\circ} \mathrm{C}$ based on curve $\mathrm{A}$, and the crystallization

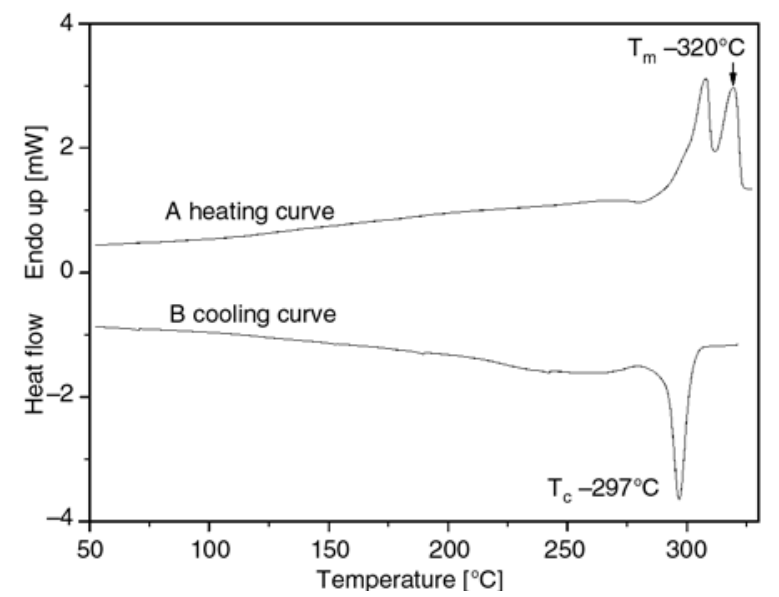

Figure 4. DSC curves of PA10N

Table 1. Elemental analysis data of PA10N

\begin{tabular}{|l|c|c|c|c|c|c|c|c|}
\hline \multirow{2}{*}{ Sample } & \multicolumn{2}{|c|}{ Carbon [\%] } & \multicolumn{2}{c|}{ Hydrogen [\%] } & \multicolumn{2}{c|}{ Nitrogen [\%] } & \multicolumn{2}{c|}{ Oxygen [\%] } \\
\cline { 2 - 9 } & calculated & measured & calculated & measured & calculated & measured & calculated & measured \\
\hline PA10N & 75.0 & 74.9 & 7.95 & 8.01 & 7.95 & 7.91 & 9.10 & 9.18 \\
\hline
\end{tabular}




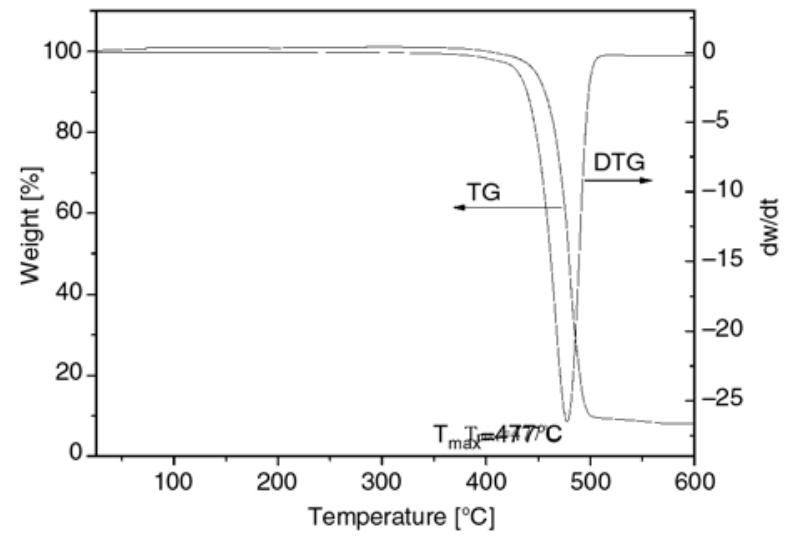

Figure 5. TGA curves of PA10N

temperature $\left(T_{c}\right)$ of $\mathrm{PA} 10 \mathrm{~N}$ is $297^{\circ} \mathrm{C}$ based on curve B.

TGA curves of PA10N are shown in Figure 5. The curve A of PA10N shows a one-stage weight loss process in nitrogen. The decomposition temperature $\left(T_{d}\right)$ of PA10N is approximately $495^{\circ} \mathrm{C}$, and the termination temperature of thermal degradation is about $500^{\circ} \mathrm{C}$. The maximum degradation temperature $\left(T_{\max }\right)$ of PA $11 \mathrm{~N}$ is $477^{\circ} \mathrm{C}$.

The $T_{m}$ of PA10N is far below $T_{d}$ of PA10N. Therefore, the melt processing ability of PA10N is excellent. In addition, the $T_{d}$ of PA10N is higher than that of aliphatic polyamides $[30,31]$. The results show that the thermal stability of PA10N has been improved by inserting naphthalene linkage into the polymeric backbone.

DMA was also used to characterize the thermal property of PA10N (Figure 6). Three obvious transition peaks can be observed, and are defined as $\alpha$, $\beta$ and $\gamma$ relaxation, respectively. The glass transition temperature $\left(T_{g}\right)$ of the PA10N is $144^{\circ} \mathrm{C}$ according to $\alpha$ relaxation. $T_{g}$ of aliphatic polyamides such as poly ( $\varepsilon$-caprolactam) (nylon6) $\left(T_{g}=60^{\circ} \mathrm{C}\right)$ and poly(hexamethylene adipamide) (nylon66) $\left(T_{g}=\right.$ $50^{\circ} \mathrm{C}$ ) are all below $90^{\circ} \mathrm{C}$. The results show that $T_{g}$ of PA10N is higher than those of aliphatic polyamides. As expected, the heat-resistance of

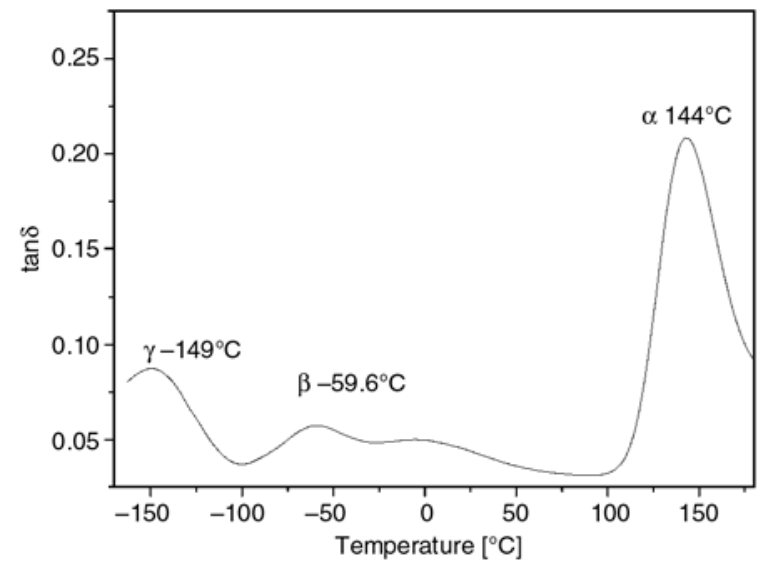

Figure 6. DMA curve versus temperature of PA10N $(1 \mathrm{~Hz})$

PA10N was improved by the introduction of naphthalene-ring. The $\beta$ relaxation reflects the mobility of carbonyl group of amorphous region, and the $\gamma$ relaxation reflects the co-movement of amido and methane groups. The thermal data of PA10N in this work are listed in Table 2.

\subsection{Mechanical properties of PA10N}

All dry and standard samples of PA10N for mechanical tests were prepared by injection molding in an injection-molding machine. Based on Table 3, it can be observed that the tensile strength of PA10N is almost as same as that of PA9T at room temperature [32].

\subsection{Flash Py-GC/MS analysis}

A typical pyrogram of PA10N (total ion chromatogram of the pyrolysates) obtained by flash pyrolysis at $700^{\circ} \mathrm{C}$ is shown in Figure 7. The pyrolysates were identified by mass spectra and confirmed by comparing their retention times [33-37]. The results of identification, the molecular weight and relative intensity of pyrolysis products

Table 2. The intrinsic viscosity, thermal data and water-absorbing capacity of PA10N

\begin{tabular}{|l|c|c|c|c|c|c|}
\hline Sample & $\eta\left[\mathbf{d l}^{\prime} \cdot \mathbf{g}^{-1}\right]$ & $\mathbf{T}_{\mathbf{m}}\left[{ }^{\circ} \mathbf{C}\right]$ & $\mathbf{T}_{\mathbf{c}}\left[{ }^{\circ} \mathbf{C}\right]$ & $\mathbf{T}_{\mathbf{d}}\left[{ }^{\circ} \mathbf{C}\right]$ & $\mathbf{T}_{\mathbf{g}}\left[{ }^{\circ} \mathbf{C}\right]$ & Water-absorbing capacity [\%] \\
\hline PA10N & 1.85 & 320 & 297 & 495 & 144 & 0.14 \\
\hline
\end{tabular}

Table 3. The mechanical property of PA10N compared with PA9T

\begin{tabular}{|l|c|c|c|c|c|c|}
\hline \multicolumn{1}{|c|}{ Samples } & $\begin{array}{c}\text { Tensile } \\
\text { strength } \\
{[\mathbf{M P a}]}\end{array}$ & $\begin{array}{c}\text { Tensile } \\
\text { modulus } \\
{[\mathbf{G P a}]}\end{array}$ & $\begin{array}{c}\text { Breaking } \\
\text { elongation } \\
{[\%]}\end{array}$ & $\begin{array}{c}\text { Bending } \\
\text { strength } \\
{[\mathbf{M P a}]}\end{array}$ & $\begin{array}{c}\text { Bending } \\
\text { modulus } \\
{[\mathbf{G P a}]}\end{array}$ & $\begin{array}{c}\text { Izod impact } \\
\text { strength } \\
{\left[\mathbf{k J} \cdot \mathbf{m} \mathbf{-}^{-2}\right]}\end{array}$ \\
\hline PA10N & 94 & 1.7 & 40 & 92 & 1.9 \\
\hline PA9T & 92 & - & 20 & 120 & 2.6 \\
\hline
\end{tabular}




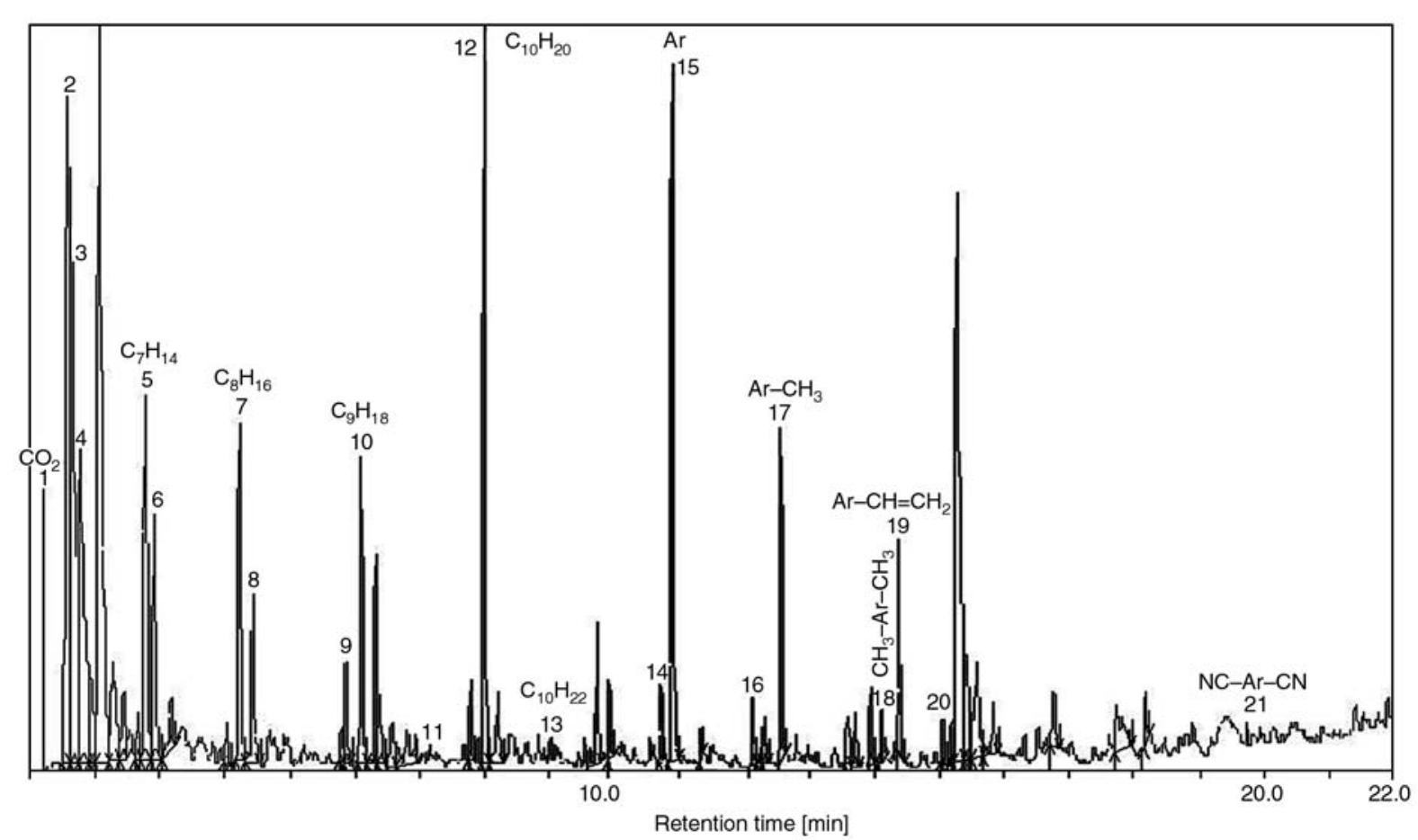

Figure 7. Py-GC/MS chromatogram of PA10N at $700^{\circ} \mathrm{C}$

Table 4. Analysis results of PA10N by Py-GC/MS

\begin{tabular}{|r|l|c|c|c|c|}
\hline No. & \multicolumn{1}{|c|}{ Tentative compounds } & $\begin{array}{c}\text { Molecular } \\
\text { weight }\end{array}$ & $\begin{array}{c}\text { Retention time } \\
{[\mathbf{m i n}]}\end{array}$ & Formula & $\begin{array}{c}\text { Relative intensity } \\
{[\%]}\end{array}$ \\
\hline 1 & Carbon dioxide & 44 & 1.57 & $\mathrm{CO}_{2}$ & 16.39 \\
\hline 2 & Pentanenitrile & 83 & 1.65 & $\mathrm{C}_{5} \mathrm{H}_{9} \mathrm{~N}$ & 3.47 \\
\hline 3 & 1 -Pentene & 70 & 1.77 & $\mathrm{C}_{5} \mathrm{H}_{10}$ & 2.95 \\
\hline 4 & 1-Hexene & 84 & 2.06 & $\mathrm{C}_{6} \mathrm{H}_{12}$ & 6.27 \\
\hline 5 & 1-Heptene & 100 & 2.77 & $\mathrm{C}_{7} \mathrm{H}_{14}$ & 2.66 \\
\hline 6 & Heptane & 112 & 2.89 & $\mathrm{C}_{7} \mathrm{H}_{16}$ & 2.81 \\
\hline 7 & 1-Octene & 114 & 4.21 & $\mathrm{C}_{8} \mathrm{H}_{16}$ & 2.15 \\
\hline 8 & Octane & 124 & 5.42 & $\mathrm{C}_{8} \mathrm{H}_{18}$ & 2.14 \\
\hline 9 & $1,8-$ Nonadiene & 126 & 6.09 & $\mathrm{C}_{9} \mathrm{H}_{16}$ & 2.57 \\
\hline 10 & 1-Nonene & 128 & 7.42 & $\mathrm{C}_{9} \mathrm{H}_{18}$ & 3.07 \\
\hline 11 & Nonane & 140 & 7.98 & $\mathrm{C}_{9} \mathrm{H}_{20}$ & 3.29 \\
\hline 12 & 1-Decene & 125 & $\mathrm{C}_{10} \mathrm{H}_{20}$ & 2.20 \\
\hline 13 & Decane & 128 & 10.71 & $\mathrm{C}_{10} \mathrm{H}_{22}$ & 2.75 \\
\hline 14 & Octanenitrile & 153 & 10.88 & $\mathrm{C}_{8} \mathrm{H}_{15} \mathrm{~N}$ & 2.49 \\
\hline 15 & Naphthalene & 142 & 12.26 & $\mathrm{C}_{10} \mathrm{H}_{8}$ & 19.62 \\
\hline 16 & Decanenitrile & 156 & 14.10 & $\mathrm{C}_{10} \mathrm{H}_{19} \mathrm{~N}$ & 2.56 \\
\hline 17 & 1-Methylnaphthalene & 154 & 14.38 & $\mathrm{C}_{11} \mathrm{H}_{10}$ & 4.57 \\
\hline 18 & 2,6-Dimethylnaphthalene & 153 & 15.28 & $\mathrm{C}_{12} \mathrm{H}_{12}$ & 2.92 \\
\hline 19 & 2-Vinylnaphthalene & 178 & 19.77 & $\mathrm{C}_{12} \mathrm{H}_{10}$ & 2.57 \\
\hline 20 & 1-Naphthalenecarbonitrile & $\mathrm{C}_{11} \mathrm{H}_{7} \mathrm{~N}$ & 9.57 \\
\hline 21 & 2,6-Naphthalene dicarbonitrile & & $\mathrm{C}_{12} \mathrm{H}_{6} \mathrm{~N}_{2}$ & 2.11 \\
\hline
\end{tabular}

are reported in Table 4 . The relative intensity is a ratio of integral shadow area among them. The weight of each sample used in the analysis is 0.1 , $0.2,0.5$ and $1 \mathrm{mg}$. Four parallel experiments were carried out for each sample with different sample weight, and no changes in relative intensity of pyrolysis product were observed. The resulting value was the average of four parallel experiments.

\subsection{The inferred thermal decomposition processes}

The bond strength of $\mathrm{C}-\mathrm{N}$ is $305 \mathrm{~kJ} \cdot \mathrm{mol}^{-1}$, which is less than the value of $346 \mathrm{~kJ} \cdot \mathrm{mol}^{-1}$ for a $\mathrm{C}-\mathrm{C}$ bond [38], so many evidences suggested that the primary polyamide chain scission occurs either at the peptide $\mathrm{C}-\mathrm{N}$ or at adjacent bonds [39]. Homolytic scission, hydrolysis, intramolecular $\mathrm{C}-\mathrm{H}$ transfer and 
cis-elimination (a particular case of $\mathrm{C}-\mathrm{H}$ transfer) are all suggested as possible primary chains-scission mechanisms [39]. Naphthalene rings are stabilized in the process of pyrolysis of PA10N, the cleavage of the $\mathrm{C}-\mathrm{N}$ amide bond and the homolytic scission of $\mathrm{C}_{\text {naphthalene }}-\mathrm{C}_{\text {amido }}$ bond were the primary pyrolysis pathways. According to the pyroly-

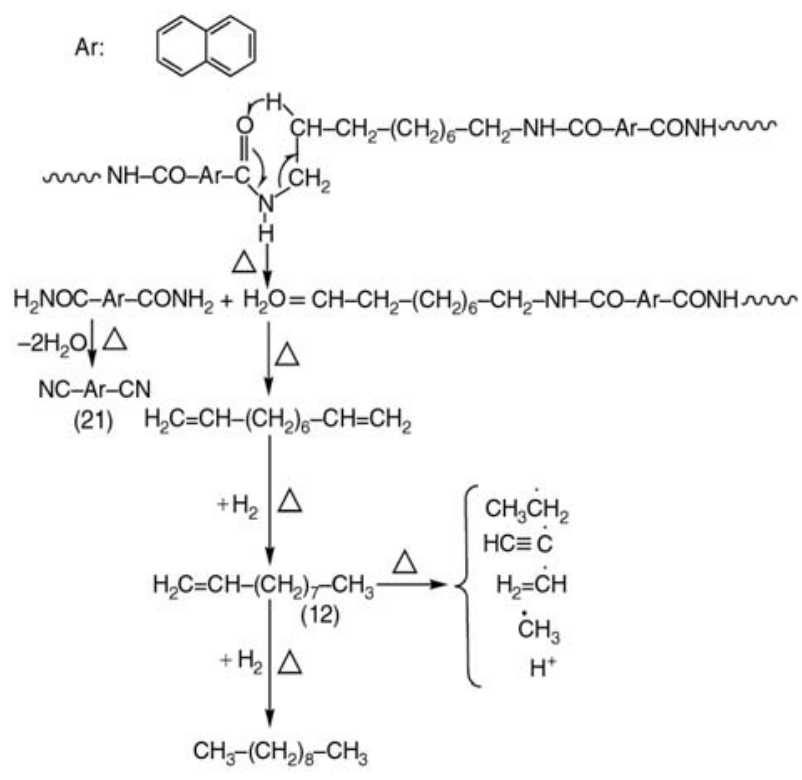

(13)

Figure 8. Thermal decomposition mechanism A of PA10N

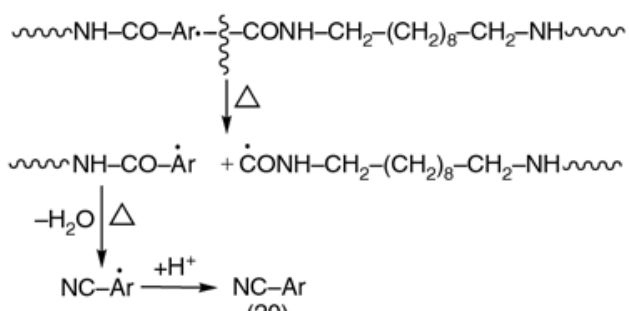

(20)

Figure 9. Thermal decomposition mechanism B of PA10N

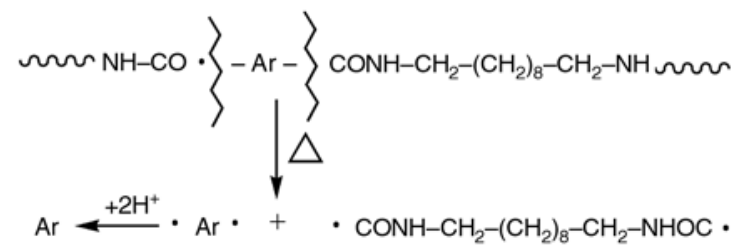

(15)

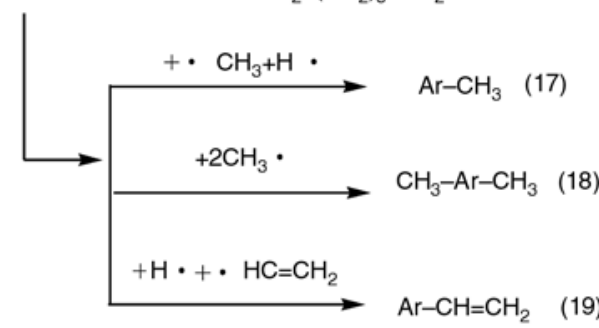

Figure 10. Thermal decomposition mechanism $\mathrm{C}$ of PA10N

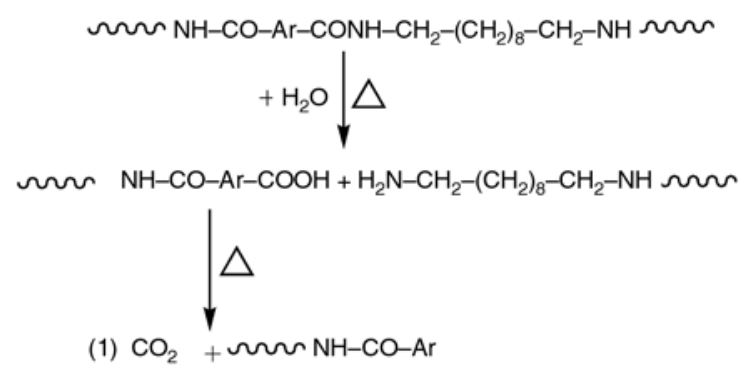

Figure 11. Thermal decomposition mechanism D of PA10N

sis products, the possible pyrolysis pathways are illustrated in Figure 8-11 (Marked as route A, B, C and $\mathrm{D}$ respectively). The four possible routes happen randomly at the same time.

Route A indicated that PA10N was decomposed via a $\beta-\mathrm{CH}$ hydrogen transfer process with formation of amide and olefin end-groups [40]. The products containing amide end-groups could further undergo thermal decompositions and produce the compounds with nitrile end-group, such as 2,6naphthalene dicarbonitrile.

Route B showed homolytic cleavage occurred at one side of the $\mathrm{C}_{\text {naphthalene }}-\mathrm{C}_{\text {amido }}$ bonds which form naphthalene amide and alkylamide radicals. Then, naphthalene amide radical reacted with hydrogen radical, alkyl radical and eliminating water. Finally, 1-naphthalenecarbonitrile was obtained.

Route $\mathrm{C}$ presented the bonds cleavage occurred at the two sides of $\mathrm{C}_{\text {naphthalene }}-\mathrm{C}_{\text {amido }}$ bonds forming the compounds containing naphthalene and alkylamide radicals. Naphthalene radical reacted with hydrogen radical, alkyl radical, and ethene radical, and then formatted naphthalene compounds.

Route D presented the amide bond leaded to hydrolysis in the presence of water which formed the $-\mathrm{NH}_{2}$ and $-\mathrm{COOH}$ end-groups [41], $-\mathrm{COOH}$ end-groups were further degraded to form $\mathrm{CO}_{2}$.

Alkenes and diolefines are easy to take part in homolytic radical scission of the $\mathrm{C}-\mathrm{C}$ bonds at high temperature to form smaller fragments. These fragments might react with benzene and benzonitrile free radical, so the alkenes and diolefines were not detected in the pyrolysis products.

\section{Conclusions}

PA10N was prepared from the reaction of 2,6naphthalene dicarboxylic acid and 1,10-decanediamine. The characterization of FT-IR, ${ }^{1} \mathrm{H}-\mathrm{NMR}$ 
spectroscopy and elemental analysis confirmed that the obtained product has the expected chemical structure and composition. $T_{m}, T_{g}$ and $T_{d}$ of PA10N are 320,144 and $495^{\circ} \mathrm{C}$, respectively. The intrinsic viscosity and inherent viscosity of PA10N are $1.85 \mathrm{dl} \cdot \mathrm{g}^{-1}$ and about $1.78 \mathrm{dl} \cdot \mathrm{g}^{-1}$, respectively. The results show that PA10N has better thermal stability than aliphatic polyamides. Py-GC/MS was used to study the pyrolysis products and thermal decomposition mechanisms of PA10N. The pyrolysis products of PA10N were mainly composed of twenty-one kinds of compounds, and the major pyrolysis process included $\beta-\mathrm{CH}$ hydrogen transfer process, main chain random scission and hydrolytic decomposition. Compared with PA9T, the low cost and good performance of PA10N demonstrate it could be a promising, heat-resisting and well processable engineering plastic and it can be a candidate nylon for the industrial production.

\section{References}

[1] Cassidy P. E.: Thermally stable polymers. Marcel Dekker, New York (1980).

[2] Persyn O., Miri V., Lefebvre J-M., Ferreiro V., Brink T., Stroeks A.: Mechanical behavior of films of miscible polyamide 6/polyamide 6I-6T blends. Journal of Polymer Science Part B: Polymer Physics, 44, 16901701 (2006).

DOI: $\underline{10.1002 / \text { polb.20825 }}$

[3] Endo M., Morishima Y., Yano S., Tadano K., Murata Y., Tsunashima K.: Miscibility in binary blends of aromatic and alicyclic polyamides. Journal of Applied Polymer Science, 101, 3971-3978 (2006).

DOI: 10.1002/app.22912

[4] Ferreiro J. J., de la Campa J. G., Lozano A. E., de Abajo J.: Polyisophthalamides with heteroaromatic pendent rings: Synthesis, physical properties, and water uptake. Journal of Polymer Science Part A: Polymer Chemistry, 43, 5300-5311 (2005).

DOI: $10.1002 /$ pola.21000

[5] Yang H. H.: Aromatic high-strength fibers. Wiley, New York (1989).

[6] Rao Y., Waddon A. J., Farris R. J.: Structure-property relation in poly ( $p$-phenylene terephthalamide) (PPTA) fibers. Polymer, 42, 5937-5946 (2001).

DOI: $10.1016 / \mathrm{S} 0032-3861(00) 00905-8$

[7] Spiliopoulos I. K., Mikroyannidis J. A., Tsivgoulis G. M.: Rigid-rod polyamides and polyimides derived from 4,3"-diamino-2',6'-diphenyl- or di(4-biphenylyl)-p-terphenyl and 4-amino-4"'-carboxy-2',6'diphenyl-p-terphenyl. Macromolecules, 31, 522-529 (1998).

DOI: $10.1021 / \mathrm{ma} 9709664$
[8] Liaw D-J., Liaw B-Y., Tseng J-M.: Synthesis and characterization of novel poly(amide-imide)s containing hexafluoroisopropylidene linkage. Journal of Polymer Science Part A: Polymer Chemistry, 37, 2629 2635 (1999).

DOI: $10.1002 /($ SICI $) 1099-0518(19990715) 37: 14$ $\leq 2629:$ :AID-POLA37>3.0.CO;2-3

[9] Liaw D-J., Hsu P-N., Chen W-H., Lin S-L.: High glass transitions of new polyamides, polyimides, and poly(amide-imide)s containing a triphenylamine group: Synthesis and characterization. Macromolecules, 35, 4669-4676 (2002). DOI: $10.1021 / \mathrm{ma} 001523 \mathrm{u}$

[10] Liaw D-J., Chang F-C., Leung M-K., Chou M-Y., Muellen K.: High thermal stability and rigid rod of novel organosoluble polyimides and polyamides based on bulky and noncoplanar naphthalene-biphenyldiamine. Macromolecules, 38, 4024-4029 (2005).

DOI: $10.1021 / \mathrm{ma} 048559 \mathrm{x}$

[11] Uddin A. J., Ohkoshi Y., Gotoh Y., Nagura M., Endo R., Hara T.: Melt spinning and laser-heated drawing of a new semiaromatic polyamide, PA9-T fiber. Journal of Polymer Science Part B: Polymer Physics, 42, 433-444 (2004). DOI: $10.1002 /$ polb. 10710

[12] Wang W., Wang X., Li R., Liu B., Wang E., Zhang Y.: Environment-friendly synthesis of long chain semiaromatic polyamides with high heat resistance. Journal of Applied Polymer Science, 6, 2036-2042 (2009). DOI: $10.1002 / a p p .30774$

[13] Wang W., Zhang Y.: Environment-friendly synthesis of long chain semiaromatic polyamides. Express Polymer Letters, 3, 470-476 (2009).

DOI: 10.3144/expresspolymlett.2009.58

[14] Pei X., Zhao Q., Liu M., Wang Y., Wang W., Cao S.: Synthesis and characterization of two new semiaromatic polyamides. China Plastics Industrial, 33, 7-9 (2005).

[15] Liu M., Zhao Q., Wang Y., Zhang C., Li X.: Synthesis, property and application of petroleum fermentation nylon 1212. Engineering Plastics Application, 30, 37-39 (2002).

[16] Jiang T., Liu M., Fu P., Wang Y., Fang Y., Zhao Q.: Melting behavior, isothermal and nonisothermal crystallization kinetics of nylon 1111. Polymer Engineering and Science, 49, 1366-1374 (2009). DOI: $10.1002 /$ pen.21269

[17] Ng H. C.: Blends of poly(1,3-propylene 2,6-naphthalate). US Patent 6531548, USA (2003).

[18] Kuoo Y-H., Wang C-L.: Polynaphthimidazoles prepared from naphthalene dicarboxylic acid and their properties. Polymer International, 40, 93-98 (1996). DOI: 10.1002/(SICI) 1097-0126(199606)40:2<93:: AID-PI520>3.0.CO;2-B 
[19] Jian L., Sherrington D. C.: Recent developments in the synthesis, thermostability and liquid crystal properties of aromatic polyamides. Advances in Polymer Science, 111, 177-216 (1994).

DOI: $10.1007 / \mathrm{BFb} 0024129$

[20] Ballistreri A., Garozzo D., Giuffrida M., Maravigna P.: Thermal decomposition processes in aliphatic-aromatic polyamides investigated by mass spectrometry. Macromolecules, 19, 2693-2699 (1986).

DOI: $10.1021 / \mathrm{ma} 00165 \mathrm{a} 005$

[21] Gao L., Liu M., Zhao Q., Wang Y., Yang X., Cao S.: Thermal degradation process and mechanism of poly(dodecamethyleneterephthalamide) (in Chinese). Polymer Materials Science and Engineering, 18, 129132 (2002).

[22] Liebman S. A., Levy E. J.: Pyrolysis and GC in polymer analysis. Marcel Dekker, New York (1985).

[23] van Lieshout M. H. P., Janssen H-G., Cramers C. A., Hetem M. J. J., Schalk H. J. P.: Characterization of polymers by multi-step thermal desorption/programmed pyrolysis gas chromatography using a high temperature PTV injector. Journal of High Resolution Chromatography, 19, 193-199 (1996).

DOI: $\underline{10.1002 / \mathrm{jhrc} .1240190404}$

[24] Wang F. C.: Composition and structure analysis of styrene-maleic anhydride copolymer by pyrolysis-gas chromatography. Journal of Chromatography A, 765, 279-285 (1997).

DOI: $10.1016 / \mathrm{S} 0021-9673(96) 00968-5$

[25] Cui X. W., Li W. H., Yan D. Y.: Investigation on oddodd nylons based on undecanedioic acid: 1 . Synthesis and characterization. Polymer International, 53, 17291734 (2004).

DOI: $10.1002 /$ pi.1546

[26] Zou S.: Heat resistant polyamide PA9T. Modern Plastics, 12, 62-64 (2000).

[27] Li Y., Zhu X., Tian G., Yan D., Zhou E.: Multiple melting endotherms in melt-crystallized nylon 10,12 . Polymer International, 50, 677-678 (2001). DOI: $10.1002 / \mathrm{pi} .682$

[28] Ramesh C., Keller A., Eltink S. J.: Studies on the crystallization and melting of nylon 66: 3. Melting behaviour of negative spherulites by calorimetry. Polymer, 35, 5300-5302 (1994). DOI: $10.1016 / 0032-3861(94) 90483-9$

[29] Hybart F. J., Platt J. D.: The melting of 66 nylon: Observations by differential thermal analysis. Journal of Applied Polymer Science, 11, 1449-1453 (1967). DOI: $10.1002 / \mathrm{app} .1967 .070110808$

[30] Wang Y., Liu M., Zhao Q.: Studies on the process and kinetics of thermal degradation in nylon 109 (in Chinese). Polymeric Materials Science and Engineering, 15, 78-80 (1999).
[31] Zhao Q., Wang Y., Liu M., Du B., Li H., Li X..: Study on process and kinetics of thermal degradation in nylon 69 (in Chinese). Polymeric Materials Science and Engineering, 11, 52-56 (1995).

[32] Ma J. M., Song S. W., Guo J.: New heat resistance polyamide. Modern Plastics, 15, 41-44 (2003).

[33] Schulten H-R., Plage B.: Thermal degradation of aliphatic polyamides studied by field ionization and field desorption mass spectrometry. Journal of Polymer Science Part A: Polymer Chemistry, 26, 23812394 (1988).

DOI: $\underline{10.1002 / \text { pola.1988.080260911 }}$

[34] Ballistreri A., Garozzo D., Giuffrida M., Impallomeni G., Montaudo G.: Primary thermal decomposition processes in aliphatic polyamides. Polymer Degradation and Stability, 23, 25-41 (1988). DOI: 10.1016/0141-3910(89)90066-9

[35] Czégény Z., Blazsó M.: Thermal decomposition of polyamides in the presence of poly(vinyl chloride). Journal of Analytical and Applied Pyrolysis, 58, 95104 (2001). DOI: 10.1016/S0165-2370(00)00152-2

[36] Herrera M., Matuschek G., Kettrup A.: Main products and kinetics of the thermal degradation of polyamides. Chemosphere, 42, 601-607 (2001). DOI: $10.1016 / \mathrm{S} 0045-6535(00) 00233-2$

[37] Linda J. B., Michael T. K., Barry D. D., Stephen M. A.: Thermal degradation of aliphatic-aromatic polyamides: Kinetics of $N, N^{\prime}$-dihexylisophthalamide neat and in presence of copper lodide. Journal of Applied Polymer Science, 56, 803-815 (1995). DOI: $10.1002 / \mathrm{app} .1995 .070560705$

[38] Cottrell T. L.: The strengths of chemical bonds. Butterworths, London (1958).

[39] Levchik S. V., Weil E. D., Lewin M.: Thermal decomposition of aliphatic nylons. Polymer International, 48, 532-557 (1999).

DOI: 10.1002/(SICI)1097-0126(199907)48:7<532:: AID-PI214>3.0.CO;2-R

[40] Ballistreri A., Garozzo D., Maravigna P., Montaudo G., Giuffrida M.: Thermal decomposition processes in aromatic-aliphatic polyamides investigated by mass spectrometry. Journal of Polymer Science Part A: Polymer Chemistry, 25, 1049-1063 (1987).

DOI: $\underline{10.1002 / \text { pola.1987.080250411 }}$

[41] Khanna Y. P., Pearce E. M., Smith J. S., Burkitt D. T., Njuguna H., Hindenlang D. M., Forman B. D.: Aromatic polyamides. II. Thermal degradation of some aromatic polyamides and their model diamides. Journal of Polymer Science Part A: Polymer Chemistry, 19, 2817-2834 (1981). DOI: $\underline{10.1002 / p o l .1981 .170191115}$ 